\title{
La definición del territorio en las leyes y políticas ambientales nacionales entre 1973 y 2010
}

The definition of territory in environmental national laws and policies between 1973 and 2010.

\section{Candela de la Vega}

Lic. en Ciencia Política (UCC).

Maestranda en Administración Pública (IIFAP-UNC). Becaria SeCyT-UNC.

Integrante del Colectivo de Investigación

"El llano en llamas" - Facultad de Ciencia Política y Relaciones Internacionales de la Universidad Católica de Córdoba (UCC) - Instituto de Investigación en Administración Pública (IIFAP) de la Universidad Nacional de Córdoba (UNC). cande_dlv@yahoo.com.ar

\section{Recibido}

7.12 .12

\section{Aprobado}

26.3.13

\section{Resumen}

Este artículo elabora un análisis diacrónico de las leyes y políticas nacionales de Argentina en materia ambiental entre la década de 1970 y la primera década de 2000 en Argentina, en tanto las mismas constituyen instancias de cristalización de una definición estatal del territorio. Se sostiene que la definición del territorio y el ambiente están estrechamente ligadas a las características del régimen político imperante, a sus percepciones ideológicas o doctrinarias y a la mayor o menor gravitación de las líneas conceptuales predominantes en la escena internacional. A tales efectos el artículo distingue en las cuatro décadas sometidas a análisis la existencia de cinco momentos diferenciados, correspondientes a otras tantas experiencias de gobierno asentadas en específicas constelaciones de fuerzas. El análisis permite concluir que es posible identificar, en las leyes y políticas definidas como ambientales por el por el propio estado nacional, ciertos sedimentos generales que estructuran la definición del territorio como también determinadas pautas de relación entre sociedad, naturaleza y estado.

Palabras clave: Políticas ambientales, Leyes ambientales, Estado, Territorio, Conflicto. 


\begin{abstract}
This article develops a diachronic analysis of Argentina's environmental laws and national policies from the 1970s to the first decade of 2000, insofar as they constitute instances of crystallization of a state's definition of territory. Our argument asserts that as institutional definitions of both territory and environment are linked to the type of political regime, its ideological or normative perceptions as well to the gravitation of the prevailing conceptual lines in the international arena. Five specific moments are identified within the four decades under scrutiny, according to differences in the governments' performances and their supporting coalitions of forces. Accordingly, what the state names as environmental laws and policies are privileged standpoints to find out the overall ideological sediment that structure the state's definition of territory as well the relational patterns between society, nature and the state.
\end{abstract}

Key words: enviromental policies, enviromental laws, state, territory, conflict.

\title{
Introducción
}

Este artículo plantea un análisis diacrónico de las leyes y políticas nacionales en materia ambiental entre la década de 1970 y la primera década de 2000, en tanto las mismas constituyen instancias de cristalización de una definición estatal del territorio. Como se mostrará a lo largo del desarrollo, en las leyes y políticas nominadas como "ambientales" por el propio estado nacional es posible rastrear ciertos sedimentos generales que estructuran la definición del territorio como también de unas determinadas pautas de relación entre sociedad, naturaleza y estado.

Desde nuestra perspectiva, el territorio no es un lugar neutral, una mera plataforma de la acción social, sino fundamentalmente una categoría de lo político. En este sentido, el espacio mismo es el resultado de cierto estado de relaciones sociales, constituyéndose en el ámbito en el que entran en juego un conjunto de lógicas, lenguajes, valores y prácticas que interactúan y se contradicen, se superponen y disputan, definiendo y significando a ese espacio. El territorio es, entonces, "una convención y una confrontación. Precisamente porque posee límites, posee fronteras; es un espacio de conflictos” (Mançano Fernández, citado en Marín, 2009:188). 
El espacio tiene la característica de ser también ideológico y sapiencial ${ }^{1}$, en tanto comporta representaciones que lo conciben desde una lógica particular y desde saberes técnicos y racionales, especialmente generados desde las instituciones del poder. Parafraseando a Lefebvre, Núñez (2009) explica que las representaciones del espacio son representaciones plagadas literalmente de ideología ${ }^{2}$, porque son una producción que se adjudican grupos particulares que se apropian de un espacio para administrarlo y explotarlo. Es a través de estas mismas representaciones que se materializan ciertas concepciones de la territorialidad que engloban y sostienen el proceso de vida (Acsebrud, 2011).

En este marco, el estado, con su sistema político-institucional, condensa en sus decisiones sobre política ambiental representaciones sobre el espacio que se constituyen en un específico modo de gobierno (Ciuffolini, 2010) tanto de los comportamientos individuales y las relaciones interpersonales, como de las posibilidades y límites de los proyectos y contraproyectos de las acciones colectivas en cada territorio. Como reconoce Lander (2000), las decisiones del estado conllevan "modelos civilizatorios" específicos -que se hacen explícitos y operativas en el diseño y la implementación de leyes, políticas públicas, diseños organizacionales y otras decisiones estatales- cuya entrada y vigencia material provoca tensiones y conflictos en relación a otras definiciones posibles.

En tanto proceso de cambio y transición, una definición estatal de lo ambiental se genera históricamente en el seno de una etapa anterior, con los condicionamientos que ésta le impone. De este modo, un nuevo esquema ambiental no se deshace totalmente de las modalidades de nominación, uso y apropiación de la naturaleza, así como también de legislaciones, costumbres y marcas en la geografía espacial que caracterizaron a un esquema anterior. En virtud de ello, la transformación de los paradigmas ambientales dominantes no se plasma en las decisiones estatales como transformaciones totales y completas; de modo que en una misma ley o política pública pueden habitar antiguas y nuevos esquemas ambientales.

Esta definición del territorio que contienen las leyes y políticas constituye una construcción hegemónica históricamente situada, particularmente cambiable, contingente y producto de la estabilización de relaciones de fuerza en una época dada. En este sentido, las leyes y políticas ambientales pueden ser abordadas a través del tiempo como una historia de los poderes sobre el territorio, especialmente enfocado en las formas y sentidos de la dominación estatal. Ello obliga a mirar los cambios en conexión con las crisis y transformaciones en los regímenes económicos, sociales y políticos dominantes. En estos momentos se producen rupturas en las formas de dominación estatal, pero al mismo tiempo se abren oportunidades para que éstas adquieran una nueva cobertura y un renovado sustento de legitimidad (Ciuffolini y Núñez, 2011). 
Siguiendo estas premisas, el presente trabajo se organiza en cuatro apartados que abordan consecutivamente diferentes periodos. Comienza por remontarse a la aparición y tratamiento de la cuestión ambiental en la política pública nacional en la década de los ’70 para trazar luego un recorrido hasta los primeros 10 años del 2000. Adoptando una perspectiva comparativa en cada período, este análisis trata transversalmente cuatro dimensiones que, conjuntamente, dan cuenta de la definición estatal de lo ambiental:

a) Principales decisiones de leyes y políticas públicas: nombre de las principales leyes y políticas públicas nacionales vigentes en el periodo señalado. b) Estructura del aparato administrativo: características organizacionales de la estructura administrativa del estado nacional donde toman carácter ejecutivo las políticas y leyes.

c) Categorías de nominales del ambiente/territorio: modos de nombrar al ambiente y de concebir su condición de existencia así como su relación con la sociedad.

d) Sujetos del ambiente: qué constelaciones de sujetos se organizan, quiénes están legítimamente reconocidos para tomar decisiones y actuar en materia ambiental; qué tareas o funciones se les asigna a cada uno de ellos, qué peso tienen en esas constelaciones.

\section{El tercer gobierno peronista (1973-1976)}

Una historia y problematización de las leyes y políticas nominadas como ambientales en Argentina requiere ubicar como punto de partida la década de 1970. En sintonía con la mayoría de los estados del mundo occidental, este corte obedece a las marcas que produjeron diversos sucesos producidos a nivel internacional que, en su conjunto, contextualizan y permiten comprender el nacimiento de una "cuestión ambiental".

Este conjunto de sucesos ha sido ampliamente señalado y estudiado por la bibliografia existente. Allí se considera desde la crisis en 1973 del precio de un recurso natural estratégico para el mundo industrializado de la época como lo era el petróleo; la celebración en 1970 del primer "Día de la Tierra" (1970) y la primera conferencia de la Organización de Naciones Unidas sobre el Medio Ambiente, en la ciudad de Estocolmo (1972); hasta la fundación de los primeros partidos verdes en países europeos (Marcellesi, 2008) o el crecimiento exponencial del número de ONG's ambientalistas (Leis, 2001; Svampa, 2010). Estos sucesos marcaron el nacimiento de un "nuevo ambientalismo" (Leis, 2001), del "movimiento ambiental moderno" (Hannigan, 2009) o del "ecologismo como ideología” (Brailovsky y Foguelman, 1991; Marcellesi, 2009). También marcó la aparición de una serie de grandes libros sobre la crítica ecológica a la economía ortodoxa (Martínez Allier, 1992) e hizo florecer una nueva sensibilidad ambiental en el clima intelectual y académico (Alimonda, 2008). 
Dentro de este contexto en varios países surgen unas primarias estructuras institucionales encargadas de la cuestión ambiental (Leis, 2001; Alimonda, 2008; Díaz, 2009)³. Al igual que en otros países latinoamericanos (CEPAL, 1994; Rodríguez Becerra, 2009), estos eventos enmarcan el "reconocimiento del ambiente" como tema de intervención en la agenda gubernamental también en Argentina (Coria et.al, 1998; Díaz, 2006).

En este marco, la problemática ambiental se incorpora de manera vigorosa a la estructura administrativa del estado nacional en el tercer gobierno peronista que se inició en 1973 con la presidencia de Héctor J. Cámpora y continuó luego con la asunción de Juan Domingo Perón e Isabel Martínez de Perón (Díaz, 2009; Estrada Oyuela, 2007). Esto no significa que antes de ese año no existieran, dentro del aparato estatal, estructuras administrativas que regularan y atendieran en forma directa o indirecta a cuestiones consideradas "ambientales"; sin embargo, éstas estuvieron mucho más dispersas, e incluidas más bien en términos de áreas de salud e higiene pública, es decir, que el ambiente importaba en tanto se produjeran fenómenos de contaminación y estos afectaran en la salud de la población (Díaz, 2009) ${ }^{4}$ o enfocadas fragmentariamente en el uso compartido de recursos naturales como cuencas o ríos (Estrada Oyuela, 2007). No obstante, el gobierno peronista del ' 73 le imprimió su propia impronta y por ello merece ubicar ahí el inicio de esta historización.

El punto de inflexión lo constituyen dos circunstancias principales (Díaz, 2006). En primer lugar, la jerarquización de "lo ambiental" en la estructura administrativa, a partir de la creación de la Secretaría de Estado de Recursos Naturales y Ambiente Humano en la órbita del Ministerio de Economía $a^{5}$ Esta dependencia no sólo fue la primera con rango de Secretaría en la región, sino que tuvo la peculiaridad de pertenecer al Ministerio de Economía, condición que no logró en sus posteriores reencarnaciones. En segundo lugar, durante este gobierno se elabora por primera vez una política pública propia para el área, la Política Nacional de Medio Ambiente, plasmada en el Decreto No 4858/73.

Esta política se constituyó en el instrumento que mejor refleja el paradigma ambiental de la época, ya que, en lo que refiere al desarrollo del marcos legales, si bien se gestó un conjunto de proyectos de ley de alcance más bien específico -y no marcos normativos generales-, muchos de ellos no alcanzaron en ese momento el estatus de ley (Díaz, 2006). Vale la pena por lo tanto detenerse en ella para así observar los principales ejes de una definición de lo ambiental y del territorio. Por un lado, la fundamentación de esta política recoge en el decreto de creación el "Mensaje Ambiental a los Pueblos y Gobiernos del Mundo" -discurso de Perón pronunciado desde el exilio en Madrid en 1972- y se detiene mucho más en las causas de los problemas ambientales que en las recetas o las estrategias para remediarlos, lo que da un primer toque de distinción a las políticas ambientales del tercer peronismo. En esa explicación de las causas, la "cuestión del ambiente" aparece vinculada a la cuestión de la nación, la soberanía política 
y el desarrollo económico (Díaz, 2009). Estas categorías son las que construyeron puentes entre economía, sociedad y política, dando origen a una definición de lo ambiental muy particular.

Así, estrechamente atada a una matriz nacional popular del estado -caracterizada por la apelación a los discursos de modernización, desarrollo, integración y autonomía nacional ${ }^{6}$ - y, a su vez, al clima intelectual latinoamericano de los debates centro-periferia, el paradigma dominante marcaba que los problemas ambientales debían entenderse dentro y en relación a los límites de un espacio político y nacional. Retomando algunos lineamientos que ya habían sido establecidos por la luego derogada Constitución Nacional del año $1949^{7}$, la política ambiental iba a ser menos una política sobre los aspectos físicos o naturales del territorio, que parte de un posicionamiento del estado respecto del poder de decisión sobre un territorio definido como nacional.

Discursos de este tipo "implicaron un soterrado cuestionamiento a la división internacional del trabajo históricamente establecida entre potencias industrializadas y economías dependientes proveedoras de materias primas, e involucraron un creciente foco de tensiones en torno al control sobre las fuentes de energía y de bienes primarios estratégicos, poniendo, en lo sucesivo, a los conflictos ecológico-distributivos en el eje de la confrontación Norte-Sur" (Machado Aráoz, 2011:152). Se traza entonces una profunda conexión entre los problemas ambientales y la relación de dependencia económica de ciertos países con otros, de ahí que "la cuestión de los países del Tercer Mundo" se debe replantear en términos de la relación entre el hombre y la naturaleza. En otras palabras, la dependencia, el poder y la dominación de unas naciones sobre otras tienen que ser entendidas como resultado del establecimiento de un patrón de relaciones ambientales:

"Hoy cuando aquellas pequeñas naciones han crecido en número y constituyen el gigantesco y multitudinario Tercer Mundo un peligro mayor -que afecta a toda la humanidad y pone en peligro su misma supervivencia- nos obliga a plantear la cuestión en nuevos términos, que van más allá de lo estrictamente político, que superan las divisiones partidarias o ideológicas, $y$ entran en la esfera de las relaciones de la humanidad con la naturaleza (...) Las mal llamadas 'Sociedades de Consumo', son, en realidad sistemas sociales de despilfarro masivo, basados en el gasto (...) No menos grave resulta el hecho de que los sistemas sociales de despilfarro de los países tecnológicamente más avanzados funcionen mediante el consumo de ingentes recursos naturales aportados por el Tercer Mundo. (...) Lo 
peor es que, debido a la existencia de poderosos intereses creados por la falsa creencia generalizada de que los recursos naturales vitales para el hombre son inagotables, este estado de cosas tiende a agravarse, mientras un fantasma -el hombre- recorre el mundo devorando 55 millones de vidas humildes cada 20 meses, afectando hasta países que ayer fueron graneros del mundo y amenazando expandirse de modo fulmíneo en las próximas décadas" (Juan Domingo Perón, 1972, Mensaje Ambiental a los Pueblos y Gobiernos del Mundo).

Dentro de ese paradigma se reconoce la intervención de modelos sociales, políticos e ideológicos de organización que determinan la condición y situación del ambiente. De ahí que se reclame en términos de "soberanía política" la necesidad de que cada estado pueda definir esos modelos de organización, y por ende, sus esquemas ambientales. Precisamente, hablar de ambiente implicaba reivindicar un "derecho" al uso de los recursos naturales para alcanzar un mayor desarrollo económico. El territorio y la naturaleza adquieren así un matiz político al vincularse a las nociones de "autonomía", "soberanía", "derechos", "proyecto político". No se trata sólo de no contaminar o de evitar catástrofes sanitarias a partir del uso de la naturaleza, sino también de regular las relaciones de fuerza que implica el control, uso y distribución de los recursos naturales dentro del país, y con otros países ${ }^{8}$.

Este paradigma, no obstante, no implicó un rechazo al sistema capitalista. Pone énfasis en el carácter reformista de las experiencias populistas-desarrollistas en América Latina en las décadas de 1950 a 1970 (Svampa, 2010), que se plasmarían más bien en políticas activas vinculadas a la nacionalización de las reservas petroleras, mineras y de recursos no renovables en general, así como de otros sectores clave de la economía (transportes, telecomunicaciones, banca, etc.); el control del comercio exterior;imposición de límites y restricciones a las inversiones extranjeras y al movimiento de capitales; reformas agrarias tendientes a disminuir la concentración interna de la propiedad rural; luchas diplomáticas por el mejoramiento de los términos de intercambio de las materias primas; cartelización y control de la oferta en los mercados energéticos y de materias primas en general, entre las más importantes (Machado Aráoz, 2011).

Remarcando el perfil de la política ambiental peronista más bien como un intento de reorganizar la geografia del poder mundial, es notable la designación del territorio, específicamente de los recursos naturales, como recursos de poder, especialmente en relación a sujetos "externos" o "extranjeros". Por ello decimos que se construye una definición nacional del territorio y de la legitimidad de su control político. De ahí también que sea el estado, como único y auténtico representante de la sociedad 
-de un pueblo, como refiere la Política Nacional de Medio Ambiente-, el actor que se posiciona con una capacidad superior de orientar las acciones y disposiciones sobre él. Esta prerrogativa de decisión y acción del estado se reclama, incluso, por encima del la ciencia y de la técnica: "La concientización debe originarse en los hombres de ciencia, pero sólo puede transformarse en la acción a través de los dirigentes políticos” (Perón, loc.cit.).

En el plano mundial, como corolario simbólico de tales reivindicaciones, cabe citar la aprobación de la Resolución 1803 (XVII) de Naciones Unidas acerca de la "Soberanía Permanente sobre los Recursos Naturales" (14 de diciembre de 1962), en la que se consagraba: "el reconocimiento del derecho inalienable de todo estado a disponer libremente de sus riquezas y recursos naturales en conformidad con sus intereses nacionales, y respeto a la independencia económica de los estados"; y en la que establecía, además, que "el derecho de los pueblos y las naciones a la soberanía permanente sobre sus riquezas y recursos naturales debe ejercerse en interés del desarrollo nacional y del bienestar del pueblo del respectivo estado", afirmando que la violación de tales derechos "es contraria al espíritu y a los principios de la cooperación internacional y a la preservación de la paz".

\section{El gobierno militar (1976-1983)}

El cambio en el régimen político y en el modelo de estado que trajo aparejado la irrupción del gobierno militar afectó el tratamiento que se le dio a la cuestión ambiental en Argentina (Brailovsky y Foguelman, 1991;Andrieu, 1994; Bibiloni, 2008). Esta etapa se caracteriza por una fragmentación administrativa del tratamiento de lo ambiental a partir de la diseminación de las áreas de incumbencia de la anterior Secretaría de Estado de Recursos Naturales y Medio Ambiente hacia otras instancias del aparato administrativo. Esto llevó a un trato también disperso de temas ambientales -por ejemplo, la contaminación- por más de una órbita ministerial, lo que generó el efecto de una "indiferencia" a la cuestión ambiental por parte de las cúpulas militares.

Estrada Oyuela (2007) afirma que la disolución de la Secretaría obedeció más al prejuicio con que se miraban los temas ambientales en una época en la que se confundía a los ambientalistas con activistas subversivos de inspiración socialista. Sin embargo, este tratamiento no logró constituirse en una propuesta "eco-autoritaria" (Leis, 2001) con centralización de la cuestión ambiental en las órbitas más cerradas del estado9. Más bien fue el inicio del arraigamiento de un esquema neoliberal en la concepción y tratamiento de lo ambiental, que condujo a la invisibilización de cualquier conexión del territorio con las relaciones económicas y de poder.

En 1976 la Secretaría de Estado de Recursos Naturales y Medio Ambiente, se desarticuló y se creó en su lugar la Subsecretaría de Recursos Naturales Renovables y Ecología dentro de la órbita de la Secretaría de Estado de Agricultura y Ganadería. Luego, en 1981 las 
incumbencias ambientales se concentraron en el Ministerio de Salud Pública y Medio Ambiente, en cuyo seno se creó la Subsecretaría de Medio Ambiente. En el decreto de creación de esta Subsecretaría se fija como misión "Entender en las acciones sanitarias relacionadas con la preservación, mejoramiento del ambiente, en coordinación con los organismos que desarrollan actividades concurrentes a fin de lograr una óptima relación del hombre con su medio físico y biológico" (Decreto $N^{\circ} 42 / 81$ ).

Las acciones de este periodo se orientaron a la preservación o conservación de la naturaleza, revitalizando una concepción del ambiente desde una perspectiva sanitaria. Existió una preocupación por el control de la contaminación (especialmente en agua y aire), el saneamiento ambiental, y el ambiente laboral. Las principales áreas atendidas fueron los parques nacionales, áreas protegidas, fauna, suelos, bosques, hidrocarburos. En ellas primó la necesidad de preservación y se reglamentó su uso con énfasis en la idea de la reserva.

Así, lo ambiental se redujo significativamente a una cuestión de contaminación de la naturaleza que debe evitarse en virtud del daño sanitario que puede tener en las personas. La única relación que se visibiliza entre sociedad y ambiente es la del daño o el riesgo del mismo. Como explica Morales Lamberti (1996), para este tipo de enfoque la problemática del ambiente surge desde el momento en que se constata que cualquier intervención social determina una modificación de los componentes físicos naturales que lo circundan, que, a su vez, afecta a las condiciones sanitarias de la población. Esta concepción del ambiente desde la óptica sanitaria fue siempre el sentido más clásico y más fuerte en la definición estatal del ambiente -y lo sigue siendo- delimitando y permeando los sentidos de cualquier tipo de acción ambiental que será reconocida o legitimada en la medida en que se estructuren bajo éste código.

En esta nueva definición del ambiente hay por lo menos tres rupturas o quiebres respecto del paradigma anterior del gobierno peronista. En primer lugar, no hay aquí referencia a determinadas estructuras o modelos socioeconómicos como filtros que hacen más o menos probable, minimizan o multiplican, ese daño al ambiente. Simplemente se generaliza el riesgo de contaminación o daño sobre el ambiente a cualquier tipo de intervención humana. En segundo lugar, la necesidad de evitar el daño causado por la misma acción humana se explica en los efectos que la contaminación, por ejemplo, puede tener sobre la salud de las personas - de ahí que se trasladaran competencias ambientales de la cartera de Economía a la órbita del Ministerio de Salud y se hable de "acciones sanitarias". Por lo tanto, no son detectados otros tipos de efectos (sociales, culturales o económicos) de esos daños sobre el ambiente. Por último, esta aproximación también borra cualquier idea del ambiente y sus recursos como recurso estratégico de poder o como resultado de juegos de poder; mucho menos como un derecho de un pueblo a su control y definición. 
El paradigma del daño ambiental supone, por su parte, un estado que se ubica en el territorio con una "responsabilidad negativa (evitar el daño)" (Morales Lamberti, 1996) a través de una función de fiscalización y control. Este autoposicionamiento del estado configura una relación "estado-idílica" entre sociedad y naturaleza (Romero Lankao, 1996). De acuerdo a ella, "los componentes de la naturaleza mantiene entre sí un equilibrio, trastocado por la acción transformadora de la sociedad que ha redundado en fenómenos de contaminación y deterioro ecológicos, los cuales se pueden evitar o revertir [a través de la política ambiental]" (Romero Lankao, 1996:206).

Por último, se produjo una leve diversificación en el tipo de actores que, en el discurso estatal, se reconocían como partícipes de la intervención en la cuestión ambiental. Por un lado, la penetración profunda del paradigma de retracción y disciplinamiento del estado en favor del sector privado habilitó un discurso que involucraba también a las empresas a asumir responsabilidades de prevención y reparación del daño ambiental. Por otro lado, aun cuando la nueva matriz del estado autoritario importó, en su relación con la sociedad, un ejercicio sistemático, intenso y criminal por detectar y castigar toda forma de activación popular (Ciuffolini, 2009), se registró una aparición muy débil de núcleos organizativos relacionados con la cuestión ambiental en cierto sector de la sociedad civil (Estrada Oyuela, 2007; Díaz, 2009). Se trata de un pequeño número de asociaciones civiles o fundaciones que se mantuvieron también en la línea de conservación y preservación de algunas dimensiones del ambiente (ríos, bosques, fauna, etc.) ${ }^{10}$.

\section{Retorno a la democracia y gobierno radical (1983-1989)}

En toda Latinoamérica, la transición a regímenes democráticos representativos durante la década de 1980 fue dificil, conflictiva y marcada por situaciones socioeconómicas graves (Raza, 2000). En este marco, la recuperación de la vida democrática llevó a que las principales preocupaciones estuviesen un tanto alejadas del tema ambiental aun cuando aunque el tema figurase en ciertas plataformas electorales de 1983. La configuración de este escenario permite comprender cómo se desarrolló la política ambiental durante el gobierno de Raúl Alfonsín, y los alcances acotados de los aportes o novedades que se produjeron en la definición institucional del territorio.

Los primeros años de la gestión del gobierno radical no llegaron a cambiar el sentido que venía teniendo la política ambiental en el periodo militar. Dos aspectos siguieron contribuyendo a una débil inserción de la dimensión ambiental dentro del aparato administrativo del Estado nacional. Por un lado, una concepción parcial y fragmentada del ambiente expresada en la dispersión de atribuciones en distintas dependencias del Ministerio de Economía, de Obras y Servicios Públicos y del Ministerio de Salud y Acción Social. La defensa, conservación, recuperación y desarrollo de los recursos naturales, así como la fiscalización y el control siguieron caracterizando las funciones 
y atribuciones de estos organismos. Por otro lado, una inestabilidad de los órganos con competencias ambientales dentro del aparato estatal, marcada por cambios de dependencia o modificación de incumbencias, también contribuyó a no representar cambios respecto al periodo anterior.

Recién hacia finales de la gestión radical se produce un giro más contundente respecto a la forma en que el estado abordará la cuestión ambiental (Coria et.al, 1998; Díaz, 2009). En 1987, se crea la Subsecretaría de Política Ambiental dentro de la jurisdicción de la Secretaría General de la Presidencia, reemplazada en 1989 por la Comisión Nacional de Política Ambiental (CONAPA). Esta acción muestra un cambio en la voluntad política por jerarquizar el área dentro de la estructura del estado, aunque el final anticipado del gobierno del doctor Alfonsín, sumado a lo tardío de la medida adoptada, no favoreció la consolidación del área durante su gestión.

Asimismo, durante el periodo se muestra una ausencia de un marco regulatorio global acorde con los propósitos de la CONAPA, que sí logra sustanciarse en la siguiente década con la reforma de la Constitución Nacional. En este sentido, las provincias se adelantaron a la Nación, aprovechando la coyuntura del cambio de sus constituciones provinciales. En los albores de 1990 ya habían incorporado el principio de protección del ambiente en sus respectivas constituciones y reglamentado la materia ambiental a través de normas particulares, ya sea leyes generales de protección ambiental, o mediante normativa específica para la evaluación del impacto ambiental (Coria et.al,1998).

La noción de territorio que subyace a la política ambiental del período se aprecia en el decreto de creación de la CONAPA. Competía a ésta

"dotar de mayor estabilidad a los objetivos fundamentales de política ambiental, cuales son la preservación del ambiente natural y humano, el uso sostenido del potencial de recursos naturales del país y el mejoramiento de la calidad de vida de la población” (Decreto No 292/82).

Se advierten en este texto algunas nuevas vetas en la definición del territorio en la política ambiental. Por un lado, la noción de "preservación del ambiente natural y humano" y la "mejoramiento de la calidad de vida", siguen vinculadas a un enfoque sanitarista de la relación sociedad-ambiente, aunque habilitando una idea más amplia sobre la "salud" de las personas, de manera que las acciones de prevención y fiscalización del daño se acompañaron por tímidos intentos de intervención en las áreas de la información ambiental, la educación ambiental, participación ciudadana en la gestión del medio ambiente, entre otras. 
Por otro lado, declarar como objetivo de la política ambiental el "uso sostenido del potencial de recursos naturales del país" revela las primeras aproximaciones a las discusiones sobre sostenibilidad o sustentabilidad en el uso de la naturaleza y hacia la entrada de un nuevo campo de acción sobre el territorio: la planificación ${ }^{11}$. En consecuencia, el futuro como tiempo del territorio, comienza a aparecer como una dimensión susceptible de intervención institucional; es posible dirigir el rumbo y el ritmo colectivo del territorio en común relación con las transformaciones deseadas (Ramírez, 2007:72).

Estas incorporaciones sobre lo ambiental fueron el correlato de una serie de sucesos y discusiones a nivel internacional. Hitos de esta discusión fueron la creación del Programa de Naciones Unidas para el Medio Ambiente (PNUMA) y la amplia difusión del Informe Brundlant, también de la ONU. Diferentes análisis (Morales Lamberti, 1996; Coria, 1998; Raza, 2000; Leis, 2001; Lander, 2011) señalan que la principal contribución de este documento consistió en fusionar el ambiente con un renovado concepto de desarrollo, a través de la idea de "desarrollo sostenible" o "ecodesarrollo", que ponía énfasis en la satisfacción de las necesidades del presente sin que ello pueda comprometer o limitar la satisfacción de las necesidades de las futuras generaciones.

Apropiada rápidamente por el discurso neoliberal de la época, la sustentabilidad se interpretó como la implementación a través del mercado de una gestión ambiental extensa que implicaba un estado, aparentemente reducido, pero cuyo papel se determinaba como crucial a la hora de garantizar las regulaciones necesarias para establecer mercados ambientales.

La nueva meta de la sustentabilidad creaba un mandato con alto contenido normativo y ético (Leff, 1986; Coria, 1998; CEPAL, 2000; Raza, 2000; Leis, 2001) en la intervención de lo ambiental, dando origen un "dispositivo tranquilizador en la medida en que logró crear la ilusión de que se estaban tomando medidas efectivas en respuesta a la crisis diagnosticada" (Lander, 2011:1). El supuesto principal que se manejaba era que el desarrollo sustentable requería una adecuación de las bases institucionales de los diferentes países. Ello implicó la exigencia a los estados de revisar sus decisiones y políticas a la luz de los impactos que éstas causarían al mismo tiempo en el ambiente y en la economía, abriendo el paraguas a una "nueva ecotecnocracia internacional” (Martínez Allier, 1992).

En este sentido, por ejemplo, la CONAPA incluía dentro de sus objetivos la canalización de apoyos técnicos de organismos internacionales y extranjeros, consolidando la entrada de un nuevo actor con capacidad de acción en el territorio. Los actores internacionales no tienen todavía una autorización de acción directa sobre el territorio más sí una función de consultoría y asesoramiento al estado. Durante el gobierno peronista el carácter central del estado con capacidad y legitimidad de acción en el territorio era indiscutible; el periodo militar mantuvo al estado como actor en una función de fiscalización 
y control, y abrió levemente el campo de lo al "sector privado" y a la "sociedad civil"; ahora, la definición del territorio en la política ambiental inserta más explícitamente a actores no nacionales como sujetos con capacidad de intervención en el territorio, que se suman a un sector ONG's que se amplió considerablemente respecto del periodo anterior (Estrada Oyuela, 2007) ${ }^{12}$.

El Informe Brundlant no consiguió definir con claridad y profundidad un conjunto de medidas y políticas válidas para todos los estados, lo que hizo que la dirección de un "territorio sustentable" se viera revestido de ambigüedades, tensiones y proyectos muy variados y contradictorios entre sí. Leis (2001) señala que de esta ambigüedad surgieron al menos tres esquemas de acción y decisión, con sus respectivas preferencias institucionales: una orientación más estatista de intervención normativa y reguladora; una orientación que prioriza la sociedad civil; y una preferencia por el mercado como motor de una sociedad sustentable. Durante la siguiente década, la política ambiental argentina transcurrirá en el vaivén entre estos tres esquemas demostrando una inscripción obediente al paradigma del "desarrollo sustentable" que emergía en estos años.

\section{El gobierno menemista (1989-1999)}

El paradigma del desarrollo sostenible consolidó su presencia en esta década tanto en la legislación como en las políticas públicas y marcó los límites del contenido, la modalidad y las estrategias de definición e intervención sobre lo ambiental no sólo en Argentina, sino también en toda Latinoamérica (Romero Lankao, 1996; Raza, 2000). De hecho, este paradigma reafirmó su vigencia internacional principalmente a través de la Conferencia de Naciones Unidas para el Medio Ambiente y el Desarrollo de Río de Janeiro en 1992. Asimismo, puso en escena a nuevos actores y configuró determinadas relaciones entre ellos. De esta manera, el desarrollo sostenible significó verdaderamente un poderoso dispositivo discursivo que incluía un complejo de relaciones entre "objetos, acciones, actores, representaciones, imaginarios, pensamientos y elementos, agrupándolos y disponiéndolos conforme a una particular lógica de argumentación” (Ramírez, 2007:69).

La definición del territorio en la política ambiental durante la gestión menemista toma mayor protagonismo en 1991 cuando se crea en el ámbito de la Presidencia de la Nación la Secretaría de Recursos Naturales y Ambiente Humano (decreto Decreto No 2419/1991; luego, decretos $N^{\circ} 177 / 92$ y No 534/92) se le transfiere la antigua Comisión Nacional de Política Ambiental (CONPA). La Secretaría centralizó competencias al anexar organismos o dependencias e incumbencias, en especial, entes que atendían recursos estratégicos en procesos de privatización de empresas estatales, o lo referente a la financiación internacional de diversos proyectos. De este modo esta área fue el instrumento principal de la política ambiental menemista y, en cierta forma, continúa y profundiza las líneas de sustentabilidad que comenzaron a delinearse durante los últimos años del gobierno radical. 
La Secretaría no estuvo exenta del impacto del proceso de reforma administrativa del estado que se implementó en esos años y en ese contexto cambió su designación a Secretaría de Recursos Naturales y Desarrollo Sustentable (Decreto No 1381/96). No obstante estos ajustes, durante esta década cuando se consolida finalmente dentro del aparato del estado un espacio centralizado para el tratamiento de la cuestión ambiental. De hecho, Díaz (2009) reconoce que la principal acción en materia ambiental en este periodo estuvo orientada a la reestructuración del aparato de la administración pública. Las funciones de la Secretaría la llevaron a centralizar la definición estratégica de los lineamientos y prioridades para establecer programas en materia de manejo integrado de recursos naturales y del ambiente. En los fundamentos del decreto de creación, se advierte que estas acciones y políticas tomaron un sentido inequívoco:

"El desarrollo de la economía popular de mercado puede $y$ debe compatibilizar con el mantenimiento del equilibrio de los recursos naturales, con el mejoramiento del ambiente $y$ con la prevención y disminución de los efectos de la contaminación” (Decreto No 1381/96).

Simultáneamente, cristalizó en esta década un marco legal de fondo que respaldó las acciones del nuevo órgano ambiental. Uno de los hechos más representativos lo constituye la inclusión de nuevos artículos que atañen a la cuestión del ambiente en la reforma constitucional del año 1994 (Arts. 41, 42, 43 y 86). El primero de ellos garantiza el derecho a un ambiente sano, equilibrado y apto para el desarrollo humano, incorporando el mandato de que las actividades productivas no deben comprometer las necesidades de las generaciones futuras; instituye el concepto de presupuestos mínimos de protección ambiental, los cuales deberán ser dictados por la Nación, mientras que las provincias legislarán las normas necesarias para complementarlos. Por su parte, el art. $43^{\circ}$ garantiza el derecho a interponer acción de amparo contra todo aquel acto u omisión de autoridades públicas o de particulares que lesione, restrinja, altere o amenace derechos y garantías constitucionales; esta acción podrá ser interpuesta contra cualquier forma de riesgos o vulneración relativa a los derechos ambientales y es plausible de ser presentada por el afectado, el defensor del pueblo (art. 86 de la Constitución) o las asociaciones que propendan a esos fines.

La constitucionalización del ambiente fija una plataforma firme para la expansión del paradigma de la sustentabilidad en las decisiones de política ambiental en gran parte de Latinoamérica (CEPAL, 1994; Morales Lamberti, 1996; Gudynas, 2009; Díaz, 2009; Henríquez \& Nozica, 2012). Acompañada por un abultado paquete de leyes que va desde la regulación de la contaminación en bosques, suelos y ríos, hasta la ratificación de convenciones y tratados internacionales ${ }^{13}$; la inclusión del ambiente en el texto constitucional habilitaría renovadas iniciativas de intervención público-institucional que habrían de resumirse en la nueva consigna de "gestión ambiental" (PNUD, 1992) ${ }^{14}$. 
En este marco, se ejecuta desde el año 1994 el "Proyecto de Desarrollo Institucional Ambiental (PRODIA)", financiado por el Banco Interamericano de Desarrollo (BID) ${ }^{15}$.El proyecto se propone la implementación de un "Sistema Nacional de Medio Ambiente", integrando entes gubernamentales y no gubernamentales e incluyó componentes de política ambiental, legislación ambiental y fortalecimiento institucional; representó, en su conjunto, la plataforma desde la cual se conformó la política ambiental de la época (Andrieu, 1994; Díaz, 2009).

Las leyes y políticas nacionales que emergieron en esta época agregaron o acentuaron determinadas categorías asociadas a la definición del ambiente y redefinieron la constelación de sujetos y características de intervención que éstos detentan en el territorio. Nos detendremos a continuación en estos aspectos.

\section{a) Categorías asociadas a la definición del ambiente}

En este periodo la idea de desarrollo sostenible deviene mucho más operativa que en la década anterior, haciendo casi unívoco el sentido del ambiente a través de este concepto. Ahora bien, el concepto de desarrollo sostenible opera sobre la definición a priori de dos condiciones del ambiente que se ocultan o invisibilizan: la capitalización y objetivización de lo ambiental y, por ende, del territorio.

En primer lugar, el ambiente aparece explícitamente como función principal del mercado y de sus necesidades. Especialmente a nivel de las políticas públicas se consolidó y, al mismo tiempo, invisibilizó, un proceso de capitalización del ambiente: "La posibilidad de comprar y vender naturaleza se considera una condición previa para su explotación sostenible y su conservación a largo plazo e influye en la definición y aplicación de los derechos de propiedad y de poder dispositivo de la naturaleza" (Raza, 2000: 161). "Por capitalización se entiende la representación del medio biofísico (naturaleza y de las economías no industrializadas), así como de las esferas domésticas (naturaleza humana) como reservas de 'capital', y la codificación de estos stocks como propiedad suceptible de ser comercializada 'en el mercado', es decir, que puede venderse a un precio que represente el valor (utilidad) del flujo de bienes y servicios como factores de producción (inputs) de artículos básicos y en el consumo" (James O’Connor, apud Rodríguez Panqueva, 2011:37). La preservación, el equilibrio o la racionalidad en el uso-conceptos que inundaron las decisiones de la política ambiental argentina- adquirieron significado según fuera su contribución al funcionamiento de una economía de libre mercado ${ }^{16}$.

En segundo lugar, el ambiente también sufre un proceso de objetivización al tomar más bien la forma de un reservorio o depósito de materias primas, de activos naturales para la producción de mercancías (Romero Lankao, 1996; Escobar, 1998; Raza, 2000). La naturaleza "ya no significa una entidad autónoma, fuente de vida y de discurso, sino por el contrario, es abstraída a una posición pasiva, dependiente, delimitable, administra- 
ble como recurso natural, requerido para industria y el comercio (Ramírez, 2007:75). En este sentido, el ambiente se diluye en los diferentes elementos que lo componen: agua, tierra, bosques, fauna, minerales; cada uno de ellos adquirirá una realidad separada, externa a la sociedad, cuantificable e inteligible mediante métodos compatibles con semejante objetivación.

Pero a estos dos supuestos hay que agregar la definición del ambiente como derecho:

"Todos los habitantes gozan del derecho al ambiente
sano, equilibrado, apto para el desarrollo humano y para
que las actividades productivas satisfagan las necesidades
presentes sin comprometer las de las generaciones futuras"
(Art. $41^{\circ}$, Constitución Nacional).

Esta idea de derecho se distancia ciertamente de la idea de derecho que se podía leer en el periodo del gobierno peronista de los años setentas, ligada más bien a un derecho del estado -y, por implicación, el derecho de un pueblo/nación- a la determinación del uso y distribución de los recursos naturales; un derecho "sobre el ambiente", diríamos. La Constitución de 1994 prefirió marcar el camino de un derecho "al ambiente”. Antes que una facultad para determinar su condición, uso o distribución, el derecho "al ambiente" supone la facultad o posibilidad de goce: el portador de ese derecho puede gozar de un ambiente -o habitar un territorio- cuya condición ya fue definida previamente: la de ser "sano, equilibrado, apto para el desarrollo humano". El ambiente no se determina, se goza.

Pero además de gozarse en una perspectiva sanitarista que sigue presente en esta década - aunque expandido a través de la incorporación de nuevos conceptos como el de "desarrollo humano"17 - el ambiente se goza en tanto disponibilidad a través del tiempo de esa reserva de recursos necesarios para las actividades productivas. Se produce, entonces, un potente anudamiento entre derecho, ambiente y producción económica que consolida el funcionamiento de un sistema de producción que requiere de una constante y creciente transformación de la naturaleza y de ciclos ampliados de produccióncirculación-consumo (Delgado Ramos, 2012). El problema ambiental en este esquema no es el tipo de racionalidad económica, sino su perspectiva temporal de corto plazo; eso es lo que hay que corregir. La "cuestión ambiental” no es más que los horizontes temporales de una racionalidad económica y productiva.

\section{b) Sujetos y características de la intervención sobre el ambiente}

Lo expuesto anteriormente modifica los sentidos y alcances de la intervención sobre el ambiente, así como también los sujetos autorizados para ello: 


\section{"El daño ambiental generará prioritariamente la obligación de recomponer, según lo establezca la ley” (Art. $41^{\circ}$ Constitución Nacional).}

Este aspecto hace visible un famoso principio jurídico: "el que contamina paga". Según la interpretación que se le ha dado al mismo, cualquier daño ambiental genera un "pasivo ambiental”, es decir, una "obligación, una deuda de la restauración, mitigación o compensación por un daño ambiental o impacto no mitigado o remediado (...) que afecta de manera perceptible y cuantificable elementos naturales (físicos y bióticos) y humanos, es decir, la salud, la calidad de vida e incluso bienes públicos (Infraestructura) como parques y sitios arqueológicos" (Morales Lamberti, 2008: 11-12).

Lo anterior estructura las intervenciones de cualquier sujeto en el territorio, asignándoles, a priori, una racionalidad del tipo económico-instrumental. Los agentes pueden calcular y medir su intervención en el ambiente en base a una estimación costo-beneficio. En ese cálculo, deben otorgar un valor económico y financiero al impacto que genera su acción y, para ello, el principio del contaminador-pagador obliga a "internalizar" el valor del daño ambiental a las estructuras de costos de los agentes. Luego, hecho este cálculo, el agente decide si se inhibe de la acción o la realiza; y si genera un daño, la repara, mitiga o compensa.

Se desembocó de esta manera en la necesidad de un cuerpo central que administre, control, y gestione las diferentes dinámicas tendientes a orientar la acción social bajo un mismo parámetro. De ahí que el estado se orientó hacia el diseño de políticas, planes y programas que actuaron como agentes causales de esta nueva racionalidad económico-instrumental. De acuerdo a la CEPAL, durante esta década fue un imperativo para los estados la generación de "políticas e instituciones ambientales que se ocupen de los aspectos que el mercado no puede rectificar (generaciones futuras, daños irreversibles, etc.) y que generen señales correctas a los actores sociales y económicos. [Con ello] debiera ser posible lograr un crecimiento económico protegiendo la calidad del ambiente y la integridad del acervo de capital en su sentido más amplio" (CEPAL, 2000: 93).

El panorama de sujetos reconocidos para intervenir en el territorio se completó con una consolidación de organismos internacionales como fuente y difusión de "asistencia técnica". La reivindicación de una condición neutral de la ciencia y la tecnología fue la llave de entrada de la asistencia técnica como principal forma de intervención en el territorio. En ese momento, "La palabra técnica supuestamente destacaba dos características esenciales: se decía que la asistencia era científicamente evidente por sí misma; y se decía que era desinteresada. 'Técnica' implicaba 'meramente técnica', lo que por lo tanto significaba implícitamente que era "apolítica"” (Wallerstein, 1996:165). Ello contribuyó, entre otras cosas, a hacer del ambiente una materia neutral, o una cuestión 
"a-tópica" (Leis, 2001:108), ni a la derecha ni a la izquierda del espectro político existente (Leis, 2001; Marcellesi, 2009). Como corolario, el conflicto social y político fue erradicado de la cuestión ambiental.

Pero además, se produjeron reacomodaciones a favor del sector empresarial privado (que tomó mayor protagonismo, por ejemplo, a través de la privatización de empresas que explotaban recursos naturales como fue el caso de YPF o Gas del Estado). A ello se sumó la estimulación del crecimiento de $O N G{ }^{3}{ }^{18}$, aunque siempre bajo cierta línea de acción tutelada por el estado, y una nueva combinación de competencias con los estados provinciales -que no estaría exenta de los históricos problemas de jurisdicción entre la Nación y las provincias-, a través del Pacto Federal y el Consejo Federal del Medio Ambiente (COFEMA).

Para cerrar este periodo, es importante señalar que la contribución de esta década en materia ambiental fue justamente la de edificar y dejar en pie esta ingeniería institucional. No obstante la importancia que revistió la institucionalización de lo ambiental en el aparato administrativo, especialmente durante la primera mitad de la década, fue un tanto débil la ejecución de acciones y medidas ambientales. De hecho, las acciones de política ambiental representaron erogaciones muy bajas en el presupuesto público nacional (CEPAL, 2002, 2004) y tuvieron una orientación acotada a las áreas clásicas de protección y preservación ${ }^{19}$; al tiempo que el COFEMA y el Pacto Federal Ambiental se constituyeron en "entelequias sin roles, presupuestos ni objetivos (...) una expresión de voluntad sin operatividad” (Lamas, 1998:283); y el único instrumento económico para la gestión ambiental existente en el periodo fue tasa anual que se cobra a los generadores y operadores de residuos peligrosos en función de la Ley 24.051 de Residuos Peligrosos, promulgada en 1992.

\section{Gobiernos Alianza-Duhalde-Kirchnerista (1999 a 2010)}

En diciembre de 1999 asumió el gobierno “Alianza para el Trabajo, la Justicia y la Educación”, que creó la nueva Secretaría de Desarrollo Sustentable y Política Ambiental en el ámbito del ahora Ministerio de Desarrollo Social y Medio Ambiente ${ }^{20}$. Esto no sólo implicó un cambio de denominación oficial y de dependencia, sino que la autoridad ambiental fue desprovista de numerosas funciones, simplificándose notablemente su estructura organizativa: las Subsecretarías se redujeron de cuatro a una, las Direcciones Nacionales de ocho a tres y las Direcciones de trece a dos.

Si bien la Secretaría tendió a la implementación y vigilancia del cumplimiento de las leyes existentes, los avances en materia de política ambiental quedaron más bien en un nivel declamativo y estrechamente vinculados a las orientaciones internacionales del momento. En este sentido, la Estrategia Nacional de Desarrollo Sustentable (ENDS) formulada en el año 2001 para dar cumplimiento nacional a las directivas del Programa 
21, aprobado en la Conferencia de Naciones Unidas para el Medio Ambiente y el Desarrollo (CNUMAD) ${ }^{21}$ - retomó los objetivos de sustentabilidad y lo ubicó como “objetivo central de la sociedad y de la acción gubernamental” (SDSyPA, 2001:22). En esta época, más bien se evidenció un marcado retroceso en cuanto a la institucionalización y materialización de programas y actuaciones ambientales (Erbiti, 2011).

Tras la crisis política e institucional de 2001-2002 y la sucesión de nombres que encabezaron el Poder Ejecutivo traería otro cambio en la denominación de la Secretaría y un nuevo traslado: el Decreto 357-2002 creó la Secretaría de Ambiente y Desarrollo Sustentable (SAyDS) en el ámbito del nuevo Ministerio de Desarrollo Social (ex Ministerio de Desarrollo Social y Medio Ambiente).

La gestión de esta Secretaría adoptó casi exclusivamente un perfil orientado a garantizar la preservación y conservación de los recursos naturales y la biodiversidad a través del desarrollo de instrumentos de evaluación y control administrativo de la calidad ambiental y de la contaminación, así como del análisis y promoción de tecnologías, procesos y servicios que coadyuvaran en la preservación y cuidado del ambiente. Estas fueron las responsabilidades de la Dirección Nacional de Recursos Naturales y Conservación de la Biodiversidad, de la Dirección Nacional de Gestión Ambiental y de la posteriormente creada Dirección de Infracciones Ambientales (Decreto 2742/2003). Esta línea de actuación integró institucionalmente la perspectiva del ambiente como ámbito natural y físico afectable mediante el "daño" de la acción humana y abrió la puerta para la generación de instrumentos de gestión que concretizaran esa perspectiva manipulando u orientando el daño y la contaminación humana.

El principal instrumento fue la flamante Ley General del Ambiente No 25.675 (LGA), sancionada en 2002 durante el gobierno del presidente provisorio Eduardo Duhalde. Esta ley puso en blanco aquellos objetivos rectores que guiarían las políticas medioambientales en todo el territorio argentino: el "logro de una gestión sustentable y adecuada del ambiente, la preservación y protección de la diversidad biológica y la implementación del desarrollo sustentable", según versa su art. $1^{\mathrm{o} 22}$. Mediante el art. $4^{\circ}$ se sujeta la interpretación y aplicación de la LGA y de cualquier otra norma de política ambiental al cumplimiento de los siguientes principios: de congruencia, de prevención, precautorio, de equidad intergeneracional, de progresividad, de responsabilidad, de subsidiaridad, de sustentabilidad, de solidaridad y de cooperación ${ }^{23}$.

De acuerdo a dos autores, la LGA marca un "nuevo ciclo" de esquema ambiental (Sabsay y Di Paola, 2002) principalmente porque representó la herramienta operativa de los mandatos, supuestos y definiciones del art. $41^{\circ}$ de la Constitución Nacional. De hecho, la carga de operatividad de esta ley se afirma en su art. $3^{\circ}$, declarando asimismo una homogeneización de las acciones en todos los niveles de gobierno ${ }^{24}$. La preservación 
ambiental a través de un sistema de presupuestos mínimos $\left(\operatorname{art} .6^{\circ}\right)$; la definición del daño

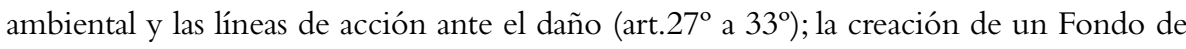
Compensación Ambiental (art.34 ) y la definición de específicos "Instrumentos de la política y la gestión ambiental" representan más que nuevas definiciones sobre el ambiente, una consecuencia lógica de los supuestos ideológicos definidos en la década anterior.

La intervención en los problemas ambientales, al conectarse con conceptos como sustentabilidad, razonabilidad o previsión/reparación del daño, se desplazó cada vez más hacia una discusión técnica y profesionalizada. De hecho, en función de lo anterior, la misma LGA introduce en sus art. $11^{\circ}$ a $13^{\circ}$ las evaluaciones de impacto ambiental como instrumentos especializados de gestión de la acción dentro del territorio. El tipo de lenguaje usado, la extensión o la forma de presentación que fueron adquiriendo estos Informes o Evaluaciones representaron, tiempo después, la demarcación de la posibilidad de una elite especializada y profesionalizada de decidir sobre el futuro o no de una intervención sobre el territorio ${ }^{25}$.

Esta impronta sanitarista, conservacionista o proteccionista del esquema de gestión ambiental del periodo se confirmará al transferir, ya durante el gobierno de Néstor Kirchner, las competencias de la Secretaría de Ambiente y Desarrollo Sustentable al ámbito del Ministerio de Salud (decretos No 141/03 y 295/03), lo que generó, posteriormente, que este último pasara a denominarse Ministerio de Salud y Ambiente (decreto 923/2004). Aunque se ampliaron y modificaron sus incumbencias, objetivos y estructura organizativa $^{26}$, la perspectiva ambiental siguió fuertemente vinculada a la concepción sanitarista del ambiente y a su condición de reserva de recursos.

Al mismo tiempo, la gestión estatal se aseguró un dispositivo poderosísimo para expandir esta concepción del ambiente: la educación ambiental. En los art. $14^{\circ}$ y $15^{\circ}$ de la LGA se estableció que la educación ambiental es "el instrumento básico para generar en los ciudadanos, valores, comportamientos y actitudes que sean acordes con un ambiente equilibrado, propendan a la preservación de los recursos naturales y su utilización sostenible, y mejoren la calidad de vida de la población" que deberá "facilitar la percepción integral del ambiente y el desarrollo de una conciencia ambiental". Esta estrategia de acción habilitó particularmente al diseño de estrategias de capacitación, formación, información y difusión de la temática ambiental y del desarrollo sustentable.

El estado asumió así la función de "tutela ambiental, protección y fomento del desarrollo sustentable" (art.1 ${ }^{\circ}$ de la LGA), considerando que "tal promoción deberá hacerse según sea el caso: regulando; liberando; induciendo o negociando“(SDSyPA, 2001:25). Con este rol del estado se van a ir delimitando otros nombres que referencian la estrategia estatal: "Ordenamiento territorial” o "gobernabilidad ambiental". El estado se va convirtiendo 
en un actor de coordinación o concertación de intereses, un regulador de las fuerzas sociales, incluyéndose a sí mismo como una fuerza más; el territorio deja de ser sólo un ámbito que hay que "reservar" para pasar a ser también un espacio para "ordenar".

Este tipo de posiciones revela un estado que asume una estrategia de intervención como coordinador de consensos en "un nuevo marco complejo en el que intervienen organismos supranacionales, niveles nacionales y subnacionales de gobierno, instituciones políticas y organizaciones locales de ciudadanos, y en donde el tema del medio ambiente se ha incorporado plenamente a la agenda de gobierno" (Torres Salcido et.al, 2008:80). Dentro de esta óptica, se trata más bien de un "estrategia competitiva que se expresaría no sólo al nivel del mercado, sino al de las instituciones orientadas al desarrollo” (Torres Salcido loc.cit).

Así, en un informe de la SAyDS del año 2004 reconoce la necesidad de reconstrucción del estado "como espacio de convocatoria para la más amplia discusión y resolución de las políticas, estrategias y cursos de acción a adoptar, para su paulatina implementación, tanto por el sector público, como por los sectores empresariales y comunitarios de la sociedad. El estado debe actuar como agente animador que, superando la desmovilización social y la pérdida de los vínculos de solidaridad, promueva el debate de un nuevo "contrato social", que identifique el camino que cada uno de sus sectores e instituciones debe recorrer, en procura de la concreción del escenario deseado” (2004:289).

En esta transformación del posicionamiento del estado también se dejó ver en las Bases para una Agenda Ambiental Nacional. Política Ambiental Sostenible para el Crecimiento y la Equidad (2004-2007). Este documento, lanzado por la SAyDS y producido en el marco del COFEMA fue el primero en asegurar su intención de alcanzar un compromiso nacional que permita enfrentar con eficacia la "[...] responsabilidad gubernamental con los ciudadanos y su ambiente, a la vez que contribuya a asegurar la participación de las organizaciones de la sociedad civil en el proceso de identificación y resolución de los principales problemas ambientales" (2004:4).

Pero el punto de quiebre que representan estas Bases radica en que deja ver una novedad en la definición del ambiente: la permeabilidad que tienen los momentos de conflicto, y especialmente del conflicto ambiental, como un ingrediente al momento de diseñar e implementar políticas y leyes ambientales. En otras palabras, hay un reconocimiento y una incorporación del conflicto social como parte del ambiente.

"El escenario actual en el que se desenvuelve la gestión de los asuntos ambientales en la Argentina se caracteriza por una singularidad que deviene de diversas transformaciones de carácter sustantivo que se produjeran en el último tiempo. En efecto, esos cambios incluyen 
en primer lugar la consolidación de la gobernabilidad en un marco de reconstrucción institucional, relacionada con la reconstitución de la legitimidad y la calidad de la arquitectura institucional democrática, luego de una crisis profunda en la cual el entero sistema político fue puesto en cuestión debido a las dudas sobre su eficacia, transparencia e integridad (...) Se trata pues de contribuir a "construir en nuestro país un capitalismo en serio. Capitalismo con reglas claras en las que el estado cumpla su rol con inteligencia, para regular, para controlar, para estar presente donde haga falta mitigar los males que el mercado no repara. Un estado que ponga equilibrio en la sociedad y que permita el normal funcionamiento del país (...) Los problemas ambientales son conflictos, y deben tratarse como tales. No reconocer la cualidad de conflicto es, en sí mismo, una parte muy importante del conflicto; e insalvable a la hora de construir consensos"

(SAyDS, 2004, Bases para una Agenda Ambiental Nacional. Política Ambiental Sostenible para el Crecimiento y la Equidad)

Efectivamente, en este periodo se registra una emergencia sostenida de conflictos ambientales en el país. Según Cotarelo el panorama del conflicto ambiental durante el periodo se puede trazar "desde mayo de 2004, [cuando] campesinos de General Pizarro, en Salta, protestan por la venta de una reserva natural (...) Pero las principales protestas fueron las de los habitantes de Esquel, en Chubut, en 2002 y 2003, y de Gualeguaychú, en Entre Ríos, en 2005” (2005:73-74). Asimismo, Seoane (2005) afirma que a partir de 2005 conflicto social en toda la región del Cono Sur comenzó a aumentar, resultado particularmente de las protestas que tienen lugar en Uruguay y Argentina, a partir del conflicto de Gualeguaychú, generado por la instalación de las plantas elaboradoras de pasta de celulosa en la margen izquierda del río Uruguay. La misma sanción de posteriores leyes ambientales como lo fueron las leyes nacionales de presupuestos mínimos de Bosques (2007) y la de Glaciares (2010) se sancionaron en un contexto explícito de controversia y conflicto público.

"Una revisión expeditiva de los principales problemas ambientales identificados en un plexo de diagnósticos sobre el estado de situación en materia ambiental en nuestro país revela que éstos en general se restringen al ambiente físico. A excepción de contadas obras que integran la cadena de causalidades, los factores del ambiente social no 
son plenamente incorporados. (...) Los componentes del ambiente físico son el aire, el agua, la calidad y condición atmosférica, las plantas, los animales, las condiciones de higiene, etc. El ambiente social incluye factores tales como el tipo y calidad de las relaciones interpersonales o intergrupales, el acceso al trabajo productivo, el acceso a la educación y a la cultura, los condicionantes externos de la participación y libertad de expresión, las influencias psico-sociales, etc. El ambiente físico se relaciona con la satisfacción de las necesidades materiales, mientras que el ambiente social con los factores externos que inciden en la probabilidad de satisfacer las necesidades no materiales" (SAyDS, 2004, Bases para una Agenda Ambiental Nacional. Política Ambiental Sostenible para el Crecimiento y la Equidad)

Hacer compatible el crecimiento económico con desarrollo sostenible -en el marco de un nuevo paradigma de "economía verde" (cf. Lander 2011; Taddei 2012) -siguió siendo una meta de la política ambiental del periodo pero ahora el ambiente no es tan sólo físico, sino también "social", como lo explican las Bases.

La visualización de diferentes actores en conflicto u oposición con las decisiones ambientales implicó también hacer permeables la institucionalidad ambiental. La cuestión de la "participación ciudadana” ya había sido marcada por la LGA (art. 19 a 21º) aunque se afirma su carácter de consulta y de opinión no vinculante. Procedimientos de consultas o audiencias públicas fueron entonces las figuras que habilitaba esta ley. Incluso, los conflictos o reclamos sociales tuvieron su correlato en dependencias institucionales; así se manifiesta el origen de, por ejemplo, la Dirección de Pueblos Originarios y Recursos Naturales (SAyDS, 2007):

"Por primera vez en la Argentina se están atendiendo reclamos de sectores sociales afectados por la contaminación ambiental, tales como las comunidades de Lules, Cinco Saltos, Zárate, Villa Inflamable, etc. Por primera vez se están consensuando las políticas públicas en los territorios con los pueblos originarios y atendiendo los reclamos históricos de los campesinos. Para esto también creamos una, el Director de esta área es werken del pueblo mapuche y fue elegido por los pueblos originarios de la Argentina". (Picolotti, 2007, Informe de la Secretaria de Ambiente y Desarrollo Sustentable al Jefe de Gabinete de Ministros). 
Pero también lo anterior requeriría una reingeniería institucional de la ubicación de la misma SAyDS. Así, se transfirió la Secretaría de Ambiente y Desarrollo Sustentable del Ministerio de Salud a la órbita de la Jefatura de Gabinete de Ministros (Decreto 830/06). En este nuevo ámbito, la SAyDS recibió nuevos recursos y facilidades para ampliar el personal lo que impulsó la definición de una nueva estructura organizativa.

Es necesario remarcar la diversificación y ampliación de actores que se produce en este periodo como resultado de la definición del territorio a través de las políticas y leyes ambientales. El estado en todos sus niveles, actores regionales nacionales o internacionales, bloques económicos internacionales, organismos internacionales de asistencia técnica, financiera, ONG's y otros actores de la sociedad civil, actores económicos e individuos (Bibiloni, 2008) son formalmente reconocidos como tales.

\section{Reflexiones finales}

El artículo ha transitado por los ejes centrales de la definición estatal del territorio que contienen las principales políticas ambientales desde la década de 1970. La tabla 1 que se muestra al final resume los aspectos más relevantes y característicos de cada periodo y permite observar las dos líneas de análisis del trabajo: una temporal que recorre la evolución de la política ambiental en cinco periodos, y una perspectiva que busca responder a las características de la definición ideológica y hegemónica del ambiente -y, por ende, del territorio- de las políticas y leyes ambientales en cada periodo. Se ha mostrado cómo cada una de esas definiciones se derivan diferentes enfoques para enfrentar los problemas ambientales que inciden y permean la conformación de las legislaciones, las instituciones, las políticas, los instrumentos, los planes y los programas.

Entre los aspectos más arraigados, durante el periodo analizado, en la definición del ambiente en la política ambiental nacional, destacan:

a) La prevalencia y vigencia profunda de la concepción sanitarista del ambiente en las decisiones estatales, y con ella, la concentración en los problemas de la contaminación como el eje central de la cuestión. Ambiente, salud, vida, contaminación; son las categorías que atraviesan discursivamente esta perspectiva. La extensión de este sentido de lo ambiental representará un marco de sentido determinante para cualquier tipo de acción sobre el territorio, incluyendo, por ejemplo, los conflictos en torno a la habilitación o no de ciertas actividades económicas (papeleras, mineras, grandes monocultivos, etc.)

b) En consonancia con lo anterior, el lugar institucional que se dio a la cuestión ambiental siempre estuvo alejado de los organismos que comandan las definiciones económicas, salvo en el gobierno peronista de 1973. El ambiente se vinculó a los ministerios de salud o de desarrollo social, para ser finalmente entronizado en una secretaría propia 
en la órbita directa del Poder Ejecutivo. Bajo un análisis institucional, lo ambiental y lo económico tuvieron pocas oportunidades de cruzarse o de vincularse como aspectos de una misma realidad.

c) Las definiciones de lo ambiental en la política pública nacional se manifiestan como una imagen especular de las definiciones y discusiones que se sucedían en los ámbitos internacionales. Prevalece en ellos la visión fisica del problema ambiental, es decir, una preocupación profunda por la contaminación física. En muchos casos, las respuestas dadas por la política ambiental nacional a los problemas ambientales han sido el producto de la reacción ante presiones o grandes reuniones internacionales bajo el auspicio de las principales organizaciones multilaterales (ONU, BID, CEPAL, BM), que aportaron recursos económicos e influyeron en la conformación de dimensiones críticas de la política ambiental. En este sentido, se puede decir que una parte sustantiva de las políticas, en sus lineamientos fundamentales, se formularon en esos escenarios internacionales y que, en todo caso, lo que se hizo en Argentina fue adaptarlas a sus condiciones particulares.

d) Es posible reconocer dos momentos de quiebres importantes en la política ambiental cuya influencia y preponderancia configuró nuevos paradigmas para entender el ambiente desde el discurso estatal:

I. La aparición del concepto de sustentabilidad fue decisivo, en cuanto impregnó el sentido de todo tipo de acciones, proyectos o programas ambientales. Merced a ese concepto la gestión ambiental, tanto desde una intervención marcadamente técnica y neutral a cargo del estado, pero como efectuada por cualquier otro actor, fue la clave de legitimación de la acción social sobre el territorio.

II. El tratamiento del conflicto social en las políticas ambientales: en el gobierno peronista de 1973-76 el territorio fue conceptualizado como un escenario de conflicto (principalmente entre actores estatales y nacionales), mientras que en la década de 1990 se afirmará la neutralidad del ambiente, su condición a-política, y el fin de los desacuerdos a su respecto. Unos años después, las políticas de ordenamiento territorial no podrán negar el conflicto dentro y por el territorio, pero sí enunciarán la necesidad de regularlo y controlarlo a través de procesos de construcción y fijación de consensos.

e) Por último, y sugiriendo nuevas áreas de indagación, las leyes y políticas ambientales enfocadas en este artículo significaron de algún modo un clima de época para el resto de políticas sobre el territorio (por ejemplo, las políticas o leyes mineras, sobre uso de agroquímicos, etc.), de modo que habilitan un análisis de las superposiciones, intensificaciones, tensiones, contrasentidos discursivos entre otras múltiples estructuras de regulación estatal del territorio. 


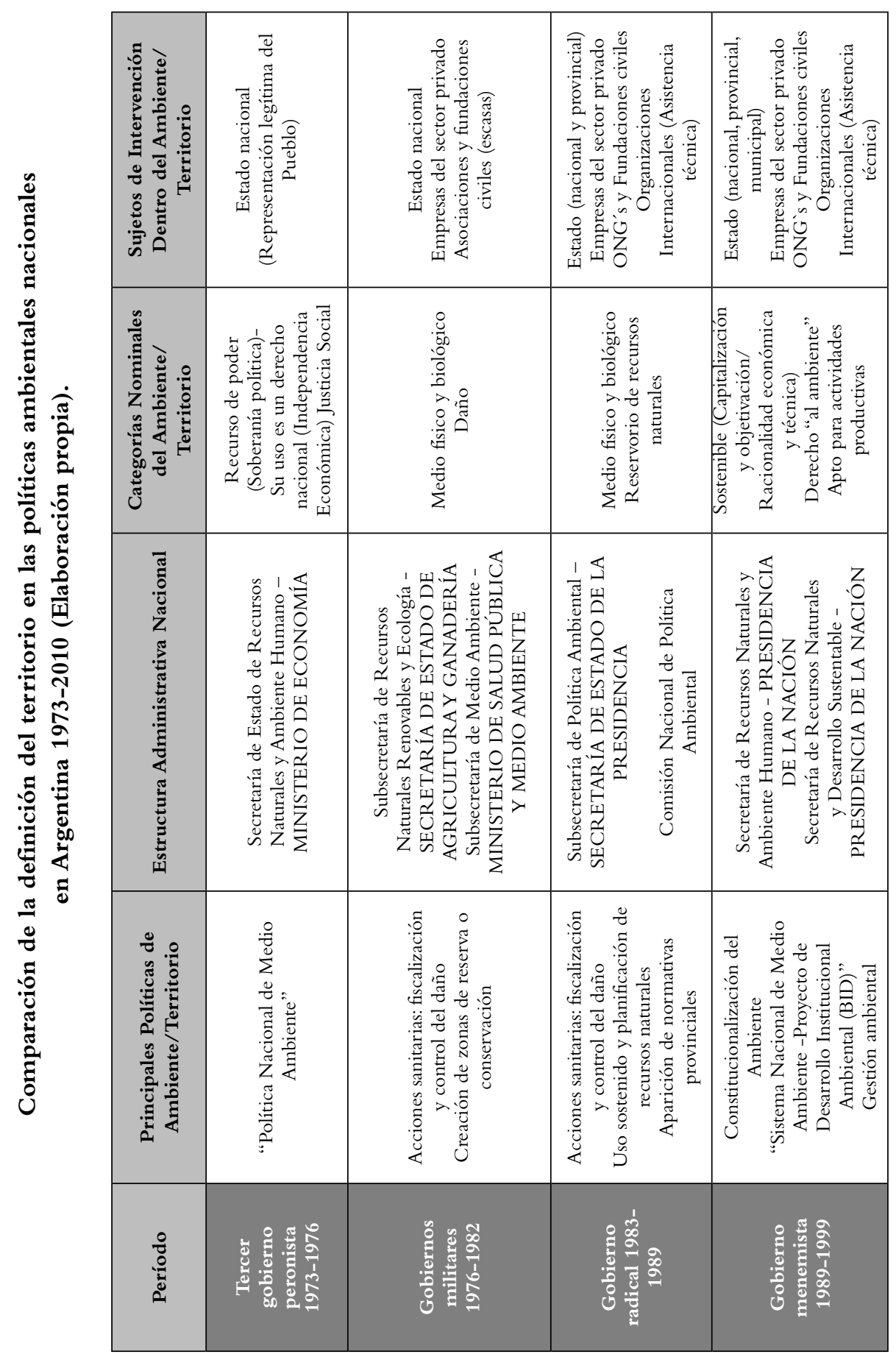




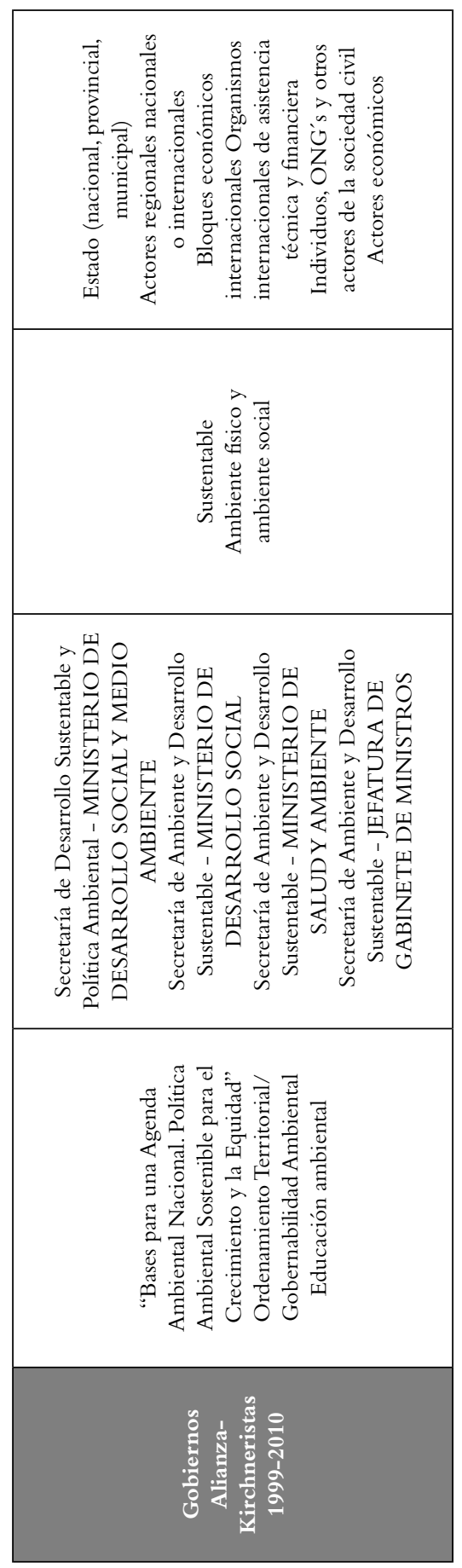




\begin{abstract}
${ }^{1}$ Martínez Allier utiliza el concepto de "lenguajes de valoración" (1992) para referirse al modo que tiene diferentes grupos sociales para hacer del territorio un espacio de significación. Por su parte, Jolly (2012) coincide en que existe una tendencia a entender el territorio como un valor o un sistema de valores que unos actores sociales le asignan a un territorio determinado, y aún como el 'sentimiento de pertenencia' a aquel. Por eso comienza a utilizar el término "territorialidad" para registrar el paso de una idea de territorio como área u objeto material, a un valor, fundamentado en la subjetividad humana. Por último, también Gudynas (2003:43) afirma que "las distintas ideas que hoy enfrentamos sobre el ambiente responden a conceptos
\end{abstract} desarrollados socialmente para entender y aprender nuestro entorno".

2 Más que una "falsa conciencia", o una mera imagen distorsionada de la realidad, con este concepto pretendemos marcar el carácter clasista y hegemónico de una producción de sentido sobre el espacio. Como ya lo decía Gramsci, se trata de "ideologías históricamente orgánicas, o sea que son necesarias para una cierta estructura (...) tienen una validez 'psicológica': 'organizan' las masas humanas, forman el terreno en el que los hombres se mueven, adquieren conciencia de su posición, luchan, etcétera” (1984: 159).

${ }^{3}$ Leis (2001) señala que según el Programa de Naciones Unidas para el Medio Ambiente (PNUMA) en 1971 apenas 12 países contaban con agencias estatales para cuidar el medio ambiente (entre ellos, Gran Bretaña, Francia, Canadá, Alemania Occidental y Estados Unidos) y diez años después eran 140 los países que habían creado órganos administrativos en esta área.

${ }^{4}$ Por ejemplo, según Nonna (2009), tal es el enfoque de la Ley nacional 2.797 de 1891, de purificación de residuos cloacales e industriales que se arrojen a los ríos.

${ }^{5}$ Asimismo, esta Secretaría tuvo su correlato en la creación de una comisión de nombre similar tanto en la Cámara de Senadores como en la Cámara de Diputados.

${ }^{6}$ Sobre esta denominación se puede ver Germani (1965); Garretón (1995); Cavarozzi (1996).

${ }^{7} \mathrm{El}$ artículo $40^{\circ}$ de esa Constitución establecía que "La organización de la riqueza y su explotación tienen por fin el bienestar del pueblo, dentro de un orden económico conforme a los principios de la justicia social. El Estado, mediante una ley, podrá intervenir en la economía y monopolizar determinada actividad, en salvaguardia de los intereses generales y dentro de los límites fijados por los derechos fundamentales asegurados en esta Constitución. Salvo la importación y exportación, que estarán a cargo del Estado, de acuerdo con las limitaciones y el régimen que se determine por ley, toda actividad económica se organizará conforme a la libre iniciativa privada, siempre que no tenga por fin ostensible o encubierto dominar los mercados nacionales, eliminar la competencia o aumentar usurariamente los beneficios. Los minerales, las caídas de agua, los yacimientos de petróleo, de carbón y de gas, y las demás fuentes naturales de energía, con excepción de los vegetales, son propiedad imprescriptibles e inalienables de la Nación, con la correspondiente participación en su producto que se convendrá con las provincias."

${ }^{8}$ En este sentido, Leis (2001) señala que este tipo de concepciones del ambiente y del territorio elaboradas desde países como Argentina, que participaron de la Conferencia de la ONU en Estocolmo en 1972, fueron las que permearon en el documento final de la misma.

${ }^{9}$ Con este concepto Leis (2001) se refiere a una línea de acción que fue propuesta en la época por cierta corriente de la teoría política ambiental y que une el tratamiento de la cuestión ambiental a un contexto de crisis económica de escasez de recursos (incluidos los recursos naturales) y a una centralización excesiva y autoritaria del poder.

${ }^{10}$ Desde 1963 existía en la Argentina la Fundación Bariloche; en 1977 se creó Vida Silvestre Argentina; en 1981, la Academia Argentina de Ciencias del Ambiente y en 1982, la Fundación para la Defensa del Ambiente (FUNAM) (Estrada Oyuela, 2007)

${ }^{11}$ Morales Lamberti (1996) sostiene que este cambio de orientación de lo ambiental se asienta en una tesis de dominio responsable de la naturaleza que reconoce no tan solo una responsabilidad negativa (evitar daños) sino también una responsabilidad positiva salvaguardando los procesos naturales en peligro por ejemplo, por medio de la investigación científica y las innovaciones tecnológicas.

${ }^{12}$ Entre las organizaciones no gubernamentales nacidas desde entonces puede citarse a la organización Amigos de la Tierra-Argentina (1984); a la Fundación Ambiente y Recursos Naturales-FARN (1985), a la filial argentina de Greenpeace (1987) y a la Fundación para la Conservación de las Especies y el Medio Ambiente-FUCEMA (1990).

${ }^{13}$ Una enumeración de las leyes vinculadas al ambiente que se crearon durante la década del ' 90 puede encontrarse en Díaz (2009).

${ }^{14}$ El PNUD (1992: 10) define la gestión ambiental como "la estrategia mediante la cual se organizan las 
actividades antrópicas que afectan el ambiente con miras a lograr el máximo beneficio social y prevenir y mitigar los problemas potenciales atacando de raíz sus causas".

${ }^{15}$ Préstamos 768/OC-AR y 907/SF-AR. Su costo total se calculó en 30 millones de dólares; 24 millones fueron aportados por el BID.

${ }^{16}$ En un documento de la época, la CEPAL, por ejemplo, también define que "el desarrollo sostenible se apoya en el reconocimiento de la función que cumple el medio ambiente y los recursos naturales como base de sustentación material, ecosistémica, ambiental y energética de los procesos económicos" (2000: 91).

${ }^{17}$ En la discusión internacional de estos años este concepto involucraba no sólo aspectos biológicos o físicos sino también educativos y económicos (cf. PNUD, 1990).

${ }^{18}$ En este período se crea el Registro Nacional de Organizaciones Ambientales (RENOA) que entre 1989 y 1995 registra la creación de 22 asociaciones sin fines de lucro, y 48 fundaciones. En total, el Registro acumula un total de 200 entidades en el periodo (Díaz, 2009). Lamas calcula que entre las ONG's registradas y las no registradas al año 1998 había unas 1200 entidades. Además, desde el Estado se promovió todo un involucramiento de las mismas en programas y proyectos con financiación nacional e internacional (Lamas, 1998; Díaz, 2009).

${ }^{19}$ Según el análisis del gasto público nacional de la CEPAL (2002) para el periodo 1994-2000 las áreas que concentran los gastos presupuestarios son protección de áreas naturales y seminaturales y protección y recuperación de suelos, aguas subterráneas y superficiales; gestión de desechos líquidos, y actividades de investigación y desarrollo.

${ }^{20}$ Decreto $\mathrm{N}^{\circ} 20-99$.

${ }^{21}$ El Programa 21 fue el documento impulsados desde la ONU que condensó recomendaciones y líneas de acción para los países, materializando un nuevo aporte al marco conceptual dentro del cual se darán los debates, negociaciones y procesos de formulación de políticas de prácticamente todos los organismos multilaterales: la economía verde.

${ }^{22} \mathrm{El}$ art. $2^{\circ}$ amplía esos objetivos a, entre otros, asegurar la preservación, conservación, recuperación y mejoramiento de la calidad de los recursos ambientales; promover el mejoramiento de la calidad de vida de las generaciones presentes y futuras; prevenir los efectos nocivos o peligrosos que las actividades antrópicas generan sobre el ambiente posibilitando la sustentabilidad ecológica, económica y social del desarrollo; establecer procedimientos y mecanismos adecuados para la minimización de riesgos ambientales, para la prevención y mitigación de emergencias ambientales y para la recomposición de los daños causados por la contaminación ambiental

${ }^{23}$ En la misma época de la sanción de la LGA se sancionaron las leyes № 25.612 de Gestión Integral de Residuos Industriales; la Ley de Presupuestos Mínimos de Protección Ambiental para la gestión de los PCBs ( $N^{\circ}$ 25.670); la Ley de Presupuestos Mínimos para la Gestión Ambiental de las Aguas N ${ }^{\circ}$ 25.688. Luego, se sancionarán la Ley de Libre acceso a la Información Pública Ambiental ( $N^{\circ}$ 25.831) y la Ley Cuenca Matanza-Riachuelo ( $\left.\mathrm{N}^{\mathrm{o}} 26.168\right)$.

${ }^{24}$ Este asunto reavivó una amplísima discusión acerca de las relaciones entre Nación y Provincia; ejemplo de estos análisis son los de Sabsay y Di Paola (2002); Bibiloni (2008), Rodríguez Salas (2012)

${ }^{25}$ Por ejemplo, según el Colectivo Voces de Alerta (2011), el Informe de Impacto Ambiental del proyecto Potasio Río Colorado, ubicado en el Departamento de Malargüe, provincia de Mendoza, “consta de 3.400 páginas. Un gran número de estas páginas se encontraban en idioma inglés, hecho que fue marcado por la Universidad Tecnológica Nacional-Sede Mendoza, encargada de realizar el dictamen técnico. Sin embargo, la empresa no solo no subsanó el tema sino que, en información presentada un año después, parte de la cual también en inglés se indicaba que 'En caso de alguna diferencia entre el texto en inglés y el español contenido en este plano, el texto en inglés tomará precedencia”" (2011:93.94).

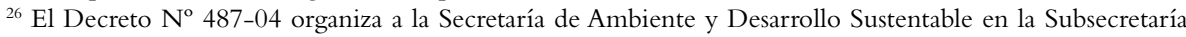
de Planificación, Ordenamiento y Calidad Ambiental y la Subsecretaría de Recursos Naturales, Normativa, Investigación y Relaciones Internacionales. 


\section{Referencias bibliográfícas}

Accesburd, E. (2011) "La naturaleza discursiva en los diferentes sectores en los conflictos mineros en Argentina”. Trabajo presentado en las IX Jornadas de Sociología, Universidad de Buenos Aires, 8-12 de agosto, sin publicar.

Alimonda, H. (2008) "Introducción", en Gestión Ambiental y conflicto social en América Latina. Buenos Aires: CLACSO, pp. 13-24.

Andrieu, P. E. (1994). "Políticas y Gestión Pública de la Preservación del Medio Ambiente en Argentina: Aspectos institucionales al nivel nacional”, en Andriue, P.E. y Tombesi, P. (comps), Política y Administración del Ambiente y Recursos Naturales en Argentina, pp. 507-523. Buenos Aires: Programa de Estudios sobre la Modernización del Estado y las Políticas Públicas en Argentina. Disponible en http://www.econ.uba.ar/www/servicios/ Biblioteca/bibliotecadigital/andrieu/pdf/CD-LIBRO-6/index6.htm consultado el 13 de diciembre de 2012.

Bibiloni, (2008) Medio Ambiente y política: una visión integradora para gestiones viables. Buenos Aires: RAP.

Brailovsky, A.E.; Foguelman, D. (1991) Memoria Verde: Historia Ecológica de la Argentina. Buenos Aires: Editorial Sudamericana.

CEPAL (1994) Políticas públicas para el desarrollo sustentable: la gestión integrada de cuencas. Disponible en http://www.eclac.org/publicaciones/xml/9/19759/lcr1399s.pdf consultado el 15 de diciembre de 2012.

CEPAL (2000) Desafíos e innovaciones en la gestión ambiental. Santiago de Chile: CEPAL. Disponible en http://www.eclac.cl/cgi-bin/getProd.asp?xml=/publicaciones/ $\mathrm{xml} / 5 / 9835 / \mathrm{P} 9835 . \mathrm{xml} \& \mathrm{xsl}=/ \mathrm{dmaah} / \mathrm{tpl} / \mathrm{p} 9 f . \mathrm{xs} l \&$ base $=/ \mathrm{dmaah} / \mathrm{tpl} /$ top-bottom.xsl consultado el 13 de diciembre de 2012.

CEPAL (2002) Gasto, inversión y financiamiento para el desarrollo sostenible en Argentina. Santiago de Chile: CEPAL. Disponible en http://www.eclac.org/ddsah/publicaciones/ xml/6/11486/lcl1758e.pdf consultado el 15 de diciembre de 2012.

CEPAL (2004) Política y gestión ambiental en Argentina: gasto y financiamiento. Santiago de Chile: CEPAL. Disponible en http://www.eclac.org/publicaciones/xml/5/20745/ lc12190e.pdf consultado el 13 de diciembre de 2012. 
Ciuffolini, M. A. (2010) Resistencias. Luchas Sociales Urbanas en Córdoba post- 2001. Córdoba: EDUCC.

Ciuffolini, M. A. y Nuñez, A. (Comp.) (2011) Política y territorialidad en tres ciudades argentinas. Buenos Aires: Ediciones El colectivo.

Ciuffolini, M.A. (2009) En el llano todo quema: movimientos y luchas urbanas y campesinas en la Córdoba de hoy. Córdoba: EDUCC.

Colectivo Voces de Alerta (AA.VV) (2011) 15 mitos y realidades de la minería transnacional en la Argentina. Guía para desmontar el imaginario prominero. Buenos Aires: El Colectivo / Herramienta.

Coria, S. (1998). “Desarrollo Sustentable”. En S. Coria et.al, El rumbo ambiental en la Argentina. Buenos Aires: Editorial Ciudad Argentina, pp. 11-60.

Cotarelo, M.C. (2005) "Recursos naturales y conflicto social en la Argentina actual". Revista OSAL, 17: 67-77.

Delgado Ramos, G. C. (2012). “Extractivismo, fronteras ecológicas y geopolítica de los recursos". Revista América Latina en movimiento, año 36: 1-4.

Díaz, M. del V. (2006). “La política ambiental argentina: su errático desarrollo”. Kairos, Año 10, no 18. Disponible en http://www.revistakairos.org/k18-archivos/Diaz\%20M.pdf consultado el 23 de abril de 2012.

Díaz, M. del V. (2009) La política ambiental argentina: entre 1973-1999. San Juan: EUSJ.

Erbiti, C. (2011) "Trayectoria de las instituciones nacionales con competencias ambientales en el periodo 1970-2010”. Ponencia presentada en Sexto Congreso Argentino de Administración Pública. Julio, Resistencia, Provincia de Chaco. Disponible en http://www.asociacionag.org.ar/pdfcap/6/ERBITI_Cecilia.pdf consultado el 12 de diciembre de 2012.

Escobar, A. (1998) La invención del Tercer Mundo. Construcción y deconstrucción del desarrollo. Bogotá: Grupo Editorial Norma.

Estrada Oyuela,R. (2007) La preocupación política por el ambiente y la administración. Revista Aportes para el Estado y la Administración Gubernamental [en línea], Año 13, $\mathrm{N}^{\circ}$ 24: 19-38. Disponible en: http://www.asociacionag.org.ar/pdfaportes/24/02.pdf consultado el 12 de diciembre de 2012. 
Garretón, M. (1995). Hacia una nueva era política. Estudios sobre las democratizaciones. Santiago de Chile: FCE.

Gramsci, A. (1984) Cuadernos desde la Cárcel. México: Ediciones Era.

Gudynas, E. (2009) “Derecho de la Naturaleza y políticas ambientales”. En Acosta, A. y Martínez, E. (comps.), Derechos de la Naturaleza, pp. 39-50. Quito: Abya-Yala.

Hannigan, J. (2009) Sociología ambiental. Petrópolis:Vozes.

Henríquez, M. \& Nozica, G. (2012) “Ejes para revisar el marco regulatorio minero argentino". Trabajo preparado para su presentación en el $6^{\circ}$ Congreso Latinoamericano de Ciencias Políticas organizado por la Asociación Latinoamericana de Ciencia Política (ALACIP).

Lamas, A. (1998) "Situación institucional: rumbo actual y deseado". En S. Coria et.al, El rumbo ambiental en la Argentina. Buenos Aires: Editorial Ciudad Argentina, pp. 257-297.

Lander, E. (2000) “Ciencias sociales: saberes coloniales y eurocéntrico”. En Lander, E. (comp.), La colonialidad del saber: eurocentrismo y ciencias sociales. Perspectivas Latinoamericanas. Buenos Aires: CLACSO, pp. 246-258.

Lander, E. (2011) "La economía verde: el lobo se viste con piel de cordero". Transnational Institute, Disponible en http://www.tni.org/es/report/la-economiaverde-el-lobo-se-viste-con-piel-de-cordero consultado el 12 de diciembre de 2012.

Leff, E. (1986) “Globalización, racionalidad ambiental y desarrollo sustentable”. Ecología y capital, México, Siglo XXI/IIS-UNAM. Disponible en http://www.ambiente.gov.ar/ infotecaea/descargas/leff08.pdf, consultado el 12 de diciembre de 2012.

Leis, H.R. (2001) Modernidad insustentable. Montevideo: Nordan.

Machado Aráoz, H. (2011) "El auge de la Minería transnacional en América Latina. De la ecología política del neoliberalismo a la anatomía política del colonialismo”, en La Naturaleza colonizada. Ecología política y minería en América Latina. Buenos Aires: CLACSO. pp. 135-179.

Marcellesi, F. (2009) "Ecología política: génesis, teoría y praxis de la ideología verde". Cuadernos Bakeaz, $N^{\circ}$ 85. Disponible en http://pdf.bakeaz.efaber.net/publication/ full_text/102/CB85_maqueta_pdf.pdf consultado el 12 de diciembre de 2012. 
Marín, C. (2009) "El 'no a la mina' de Esquel como acontecimiento: otro mundo posible”. En M. Svampa, y M. A. Antonelli (comp.), Minería transnacional, narrativas del desarrollo y resistencias sociales. Buenos Aires: Biblos, pp. 181-204.

Martínez Allier, J. (1992) De la economía ecológica al ecologismo popular. Barcelona: Icaria.

Morales Lamberti, A. (1996) Temas de Derecho Ambiental. Córdoba: Córdoba Editora.

Morales Lamberti, A. (2008) “Gestión y Remediación de Pasivos Ambientales. Políticas y Atribución de Responsabilidad”. Estudios de Derecho Ambiental,Vol. I, No 1: 6-234.

Nuñez, A. (2009) "Abrir la política urbana y las necesidades sociales. Ni empresarios, ni burócratas ni vecinos: estatalidad profunda y estatalidad extensa”. Economía, Sociedad y Territorio, vol. IX No. 30:297-347.

Coria, S.; Devia, L.; Lamas, A.; Nonna, S.;Villanueva, C. (1998) El rumbo ambiental en la Argentina. Buenos Aires: Ediciones Ciudad Argentina.

Peron, J. D. (1972) “Mensaje Ambiental a los Pueblos y Gobiernos del Mundo". Disponible en http://www.ambiente.gov.ar/?idarticulo $=5187$ consultado el 1 de julio de 2012.

Picolotti, R. (2007, julio) "Informe de la Secretaria de Ambiente y Desarrollo Sustentable al Jefe de Gabinete de Ministros". Disponible en www.ambiente.gov.ar/ archivos/.../071107_informe_Romina_AF.doc consultado el 25 de noviembre de 2012.

Presidencia de la Nación (2005) Objetivos del Milenio. Informe País 2005. Proyecto PNUD/ARG/04/046

Programa de las Naciones Unidas para el Desarrollo (PNUD) (1990) Desarrollo Humano: Informe 1990. Bogotá: Tercer Mundo Editores. Programa de las Naciones Unidas para el Desarrollo (PNUD). (1992) Manual y guías para la gestión ambiental y el desarrollo sostenible. New York: CEPAL.

Ramírez, O. (2007) "El espejo invertido de la realidad: del discurso del desarrollo a la apología de la gestión ambiental”. Avá Revista de Antropología, 10:66-77.

Raza, W. (2000) "Desarrollo capitalista, neoliberalismo y ambiente en América Latina: Una breve sinopsis”. Ecología Política, 20:153-165. 
Rodríguez Becerra, M. (2009) “¿Hacer más verde al Estado colombiano?”. Revista de Estudios Sociales, $\mathrm{N}^{\circ} 32: 18-33$.

Rodríguez Panqueva, D. (2011) Capitalismo Verde. Una mirada a la estrategia de BID en cambio climático. Bogotá: Censat Agua Viva.

Rodríguez Salas, G. (2012) "Situación de la política y la gestión ambiental en la Argentina Federal", en de los Santos Gómez (coord.), El ambiente en la Argentina del Bicentenario. Buenos Aires: AbeledoPerrot, pp. 33-60.

Romero Lankao, P. (1996) "Visión y esquemas de gestión estatal de lo ambiental. ¿Sustentadores de una política racional?”. Revista Política y Cultura, 17: 203-217.

Secretaría de Ambiente y Desarrollo Sustentable (SAyDS) (2004, Marzo) "Bases para una agenda ambiental nacional. Política ambiental sostenible para el crecimiento y la equidad". Ministerio de Salud. Disponible en http://aplicaciones.medioambiente. gov.ar/archivos/web/biblioteca/File/documentos_secretara/base_agenda_ambiental_ nac.pdf consultado el 25 de noviembre de 2012.

Secretaría de Ambiente y Desarrollo Sustentable (SAyDS) (2004). "GEO Argentina 2004. Perspectivas de Medio Ambiente en Argentina”. PNUMA-SAyDS. Ministerio de Salud. Disponible en http://www.ambiente.gov.ar/archivos/web/GEO/ File/Geo_Argentina_2004.pdf consultado el 4 de octubre de 2012.

Secretaría de Ambiente y Desarrollo Sustentable (SAyDS) (2005) "Sistema de indicadores de desarrollo sostenible Republica Argentina". PNUMA-SAyDS. Ministerio de Salud. Disponible en http://www.ambiente.gov.ar/archivos/web/Indicadores/File/ Sidsa\%20Libro\%20Final_1.pdf consultado el 8 de septiembre de 2012.

Secretaría de Ambiente y Desarrollo Sustentable (SAyDS)(2007). "Informe al Jefe de Gabinete de Ministros". Disponible en http://www.google.com.ar/url?sa $=t \mathcal{E} r c t=j \mathcal{E} q=\mathcal{E} e$

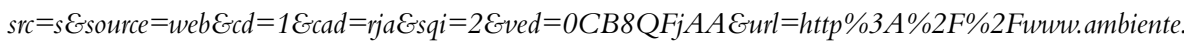
gov.ar\%2Farchivos\%2Fweb\%2FFile\%2F071107_informe_Romina_AF.docEei=8HtfUJ34Lsqu0AGW $z I D g B w E u s g=A F Q j C N H I k G g \_C z v c 2 r L t j L e \gamma 2 f Z J U E \gamma S Z A \& s i g 2=d u e m V Y B W 0 C j D f g$ Te $2 q d E C A$ consultado el 12 de diciembre de 2012.

Secretaría de Ambiente y Desarrollo Sustentable y Política Ambiental (SDSyPA). (2001). "Estrategia Nacional de Desarrollo Sustentable". Disponible en http://www.ambiente.gov.ar/archivos/web/DCSyLD/File/ends.pdf consultado el 12 de diciembre de 2012. 
Seoane, J. (2005) "Movimientos sociales y recursos naturales en América Latina: resistencias al neoliberalismo, configuración de alternativas". Revista OSAL, n 17:93-107.

Svampa, M. y Antonelli, M. (2009) (Ed.) Minería transnacional, narrativas del desarrollo y resistencias sociales. Buenos Aires: Biblos.

Svampa, M. (2010) “Entre la Obsesión del desarrollo y el giro eco-territorial”. C. Korol (comp.), Resistencias populares a la recolonización del continente (Primera Parte). Buenos Aires: América Libre, ), pp-79-106.

Sabsay, D. A. y Di Paola, M. E. (2002) "El federalismo y la nueva Ley General de Ambiente". Anales de Legislación Argentina, n 32:47-54.

Taddei, E. (2012) "Mundialización neoliberal, "nuevo internacionalismo"y coordinaciones regionales e internacionales en torno a la defensa de los bienes comunes naturales: proyecciones y significación de las experiencias populares de Nuestra América" [CLASE] En: Curso virtual "Extractivismo y resistencias sociales en Nuestra América: conflictos en torno a los bienes comunes y horizontes emancipatorios" (Programa Latinoamericano de Educación a Distancia, Centro Cultural de la Cooperación, Buenos Aires, Junio 2012).

Torres Salcido, G.; Ramos Chávez, H. (2008) “Gobernanza y territorios. Notas para la implementación de políticas para el desarrollo". Revista Mexicana de Ciencias Políticas y Sociales,Vol. L, Núm. 203: pp. 75-95.

Wallerstein, I. (1996) Después del liberalismo. México: Siglo XXI. 